\title{
Pankreatik Lenfoma Olgusunda Çok Kesitli Bilgisayarlı Tomografi ve Pozitron Emisyon Tomografi - Bilgisayarlı Tomografi Bulguları
}

\author{
Zehra I. Haşıloğlu, Nuri Havan, Recai Duymuş, Hakan Kefeli, Ufuk DG Demirkıran \\ Vakıf Gureba Eğitim ve Araştırma Hastanesi, Radyoloji Kliniği, Istanbul
}

\begin{abstract}
ÖZET
Pankreatik lenfoma olgusunda çok kesitli bilgisayarlı tomografi ve pozitron emisyon tomografi - bilgisayarlı tomografi bulguları

Non-Hodgkin lenfoma (NHL) sıklıkla lenfatik sistemden kaynaklanır. Gastrointestinal sistem tutulumu diğer sık tutulum bölgesidir. NHL'nın pankreas tutulumu nadirdir ve pankreatik NHL olgularının tanısı zordur. Bu sunumda amacımız, pankreatik NHL'nın çok kesitli bilgisayarlı tomografi (ÇKBT) ve pozitron emisyon tomografi-bilgisayarlı tomografi (PET-BT) bulgularını sunmaktır.

Anahtar kelimeler: Pankreas, Non-Hodgkin lenfoma, çok kesitli bilgisayarlı tomografi, pozitron emisyon tomografi-bilgisayarlı tomografi

ABSTRACT

The findings of multislice computed tomography (MSCT) and positron emission tomography-computed tomography (PET-CT) on a pancreatic lymphoma case

Non-Hodgkin lymphoma (NHL) is often caused by the lymphatic system. Gastrointestinal system involvement is the other frequent involvement region. Pancreas involvement of the NHL is uncommon and the diagnosis of pancreatic NHL cases is difficult. In this presentation our aim is the findings of multislice computed tomography (MSCT) and positron emission tomography-computed tomography (PET-CT) of pancreatic non-hodgkin lympoma.

Key words: Pancreas, Non-Hodgin lymphoma, multislice computed tomography, positron emission tomography-computed tomography
\end{abstract}

Bakırköy Tıp Dergisi 2012;8:91-94

GiRiş

$P^{3}$ ankreasın malign tümörleri büyük oranda adenokarsinom yapısındadır. Non-Hodgkin lenfoma (NHL) ise sıklıkla lenfatik sistemden kaynaklanır. NHL'ın en sık ekstranodal tutulumu ise gastrointestinal sistemdedir (1). NHL'da pankreas tutulumu nadir olup ekstranodal lenfomalarda pankreas tutulumu tüm yaş gruplarında \%0.6 olarak bildirilmiştir (2). Pankreatik NHL ile adenokarsinomun klinik ve radyolojik olarak ayırt edilmesi zordur. ileri evre malign NHL'da prognoz kötüdür. Ancak kemoterapi ile adenokarsinoma göre daha etkili tedavi sağlanmaktadır. Tedavi süreci açısından pankreasın adenokarsinom ve pankreatik NHL ayırımı klinik açıdan önemlidir. Bu

Yazıșma adresi / Address reprint requests to: Nuri Havan Vakıf Gureba Eğitim ve Araştırma Hastanesi, Radyoloji Kliniği, ìstanbul

Telefon / Phone: +90-505-923-1691

Elektronik posta adresi / E-mail address: nurihavan@hotmail.com

Geliş tarihi / Date of receipt: 3 Kasım 2010 / November 3, 2010

Kabul tarihi / Date of acceptance: 9 Mart 2011 / March 9, 2011 çalışmada, pankreatik NHL olgusunun çok kesitli bilgisayarlı tomografi (ÇKBT) ve pozitron emisyon tomografi-bilgisayarlı tomografi (PET-BT) bulguları sunulmuştur.

\section{OLGU SUNUMU}

Elli dokuz yaşında kadın hasta ara ara olan karın ağıısı yakınması ile Dahiliye polikliniğimize başvurdu. Fizik muayenesinde; sol inguinal bölgede ele gelen şişlik haricinde bulgu saptanmadı. Özgeçmişinde anlamlı bir özellik yoktu. Laboratuvar tetkiklerinde anemi ile uyumlu olarak hemoglobin değeri $10.1 \mathrm{~g} / \mathrm{dl}$ idi. Posterior-anterior akciğer grafisinde solda daha belirgin her iki tarafta hiler dolgunluk izlendi. Abdominal ÇKBT'de (General Electric LightSpeed VCT 64, Milwaukaee USA) pankreas baş ile gövde bileşkesinde $5 \times 4 \mathrm{~cm}$, kuyruk kesiminde $2 \times 2 \mathrm{~cm}$ ve dalakta büyüğü $3 \times 4 \mathrm{~cm}$ boyutlarında olmak üzere çok sayıda, düzgün sınırlı, homojen, hipodens yumuşak doku kitleleri izlendi. Kitleler kontrastlı incelemelerde homojen hafif kontrast tutmaktaydı (Resim 1A-E). Safra yollarında ve 


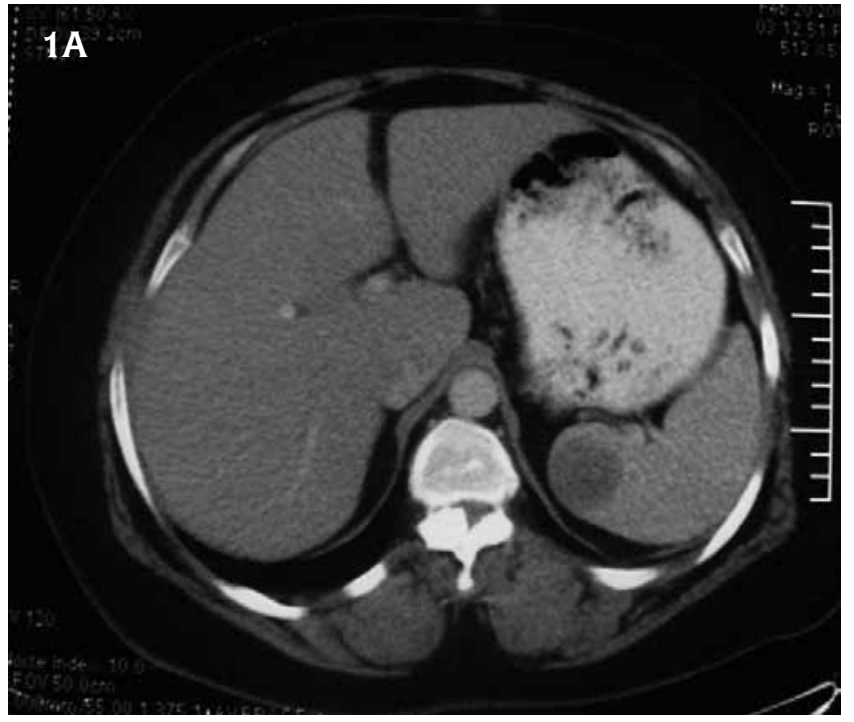

Resim 1: ÇKBT'de dalakta homojen hafif kontrast tutulumu gösteren düzgün sınırlı kitle lezyonu (A). Dalakta ve pankreasta homojen hafif kontrast tutulumu gösteren düzgün sınırlı kitle lezyonları (B,C). Pankreas boyun-korpus bileşkesinde homojen hafif kontrast tutulumu gösteren düzgün sınırlı kitle lezyonu $(\mathrm{D}, \mathrm{E})$.
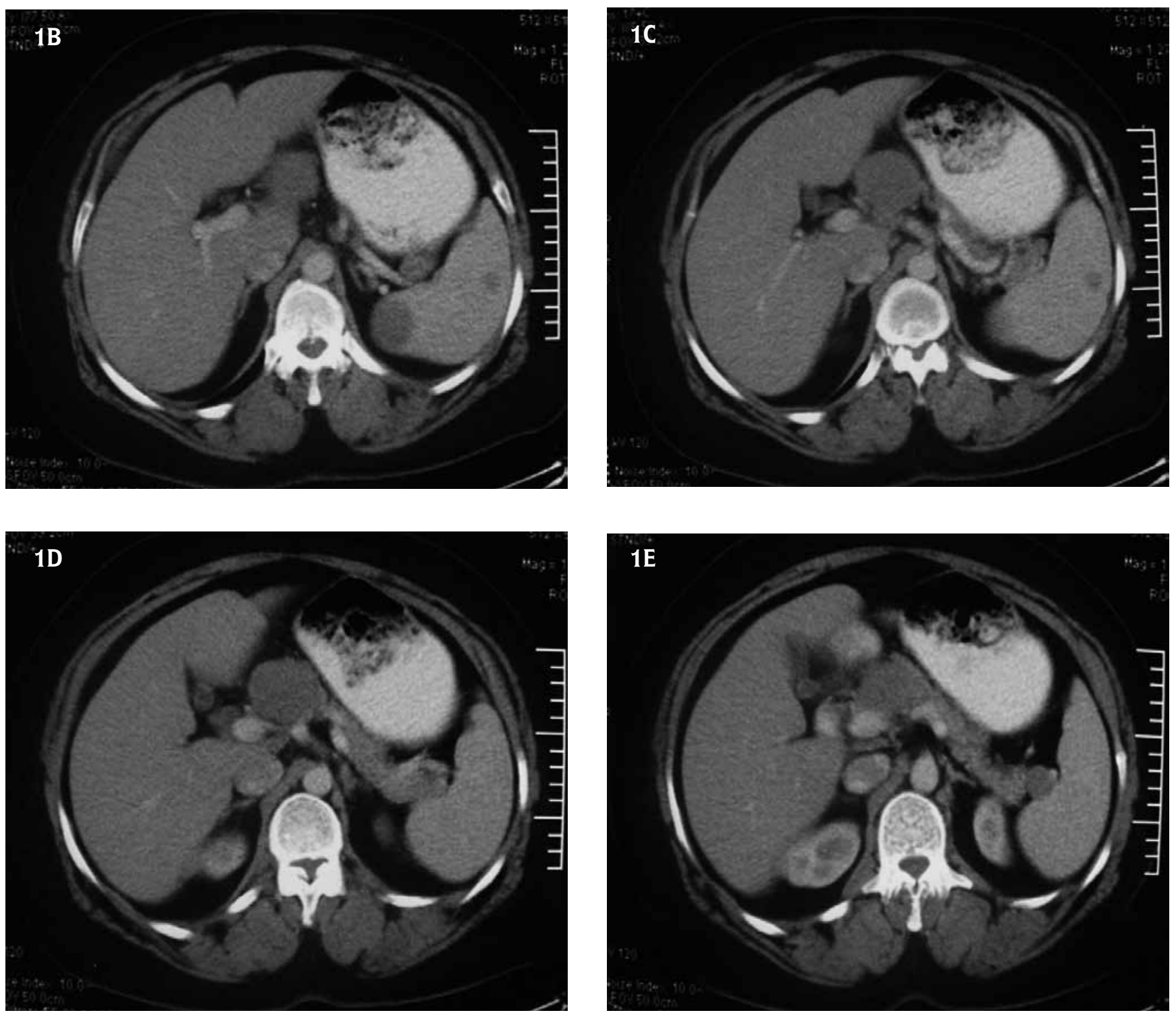


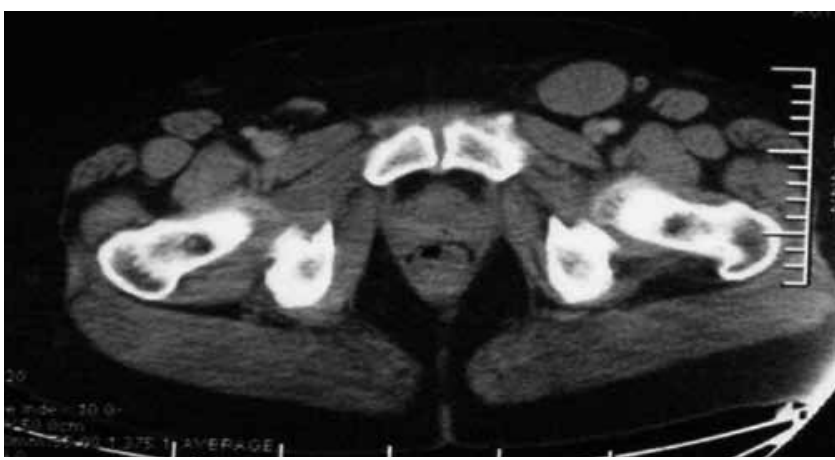

Resim 2: ÇKBT'de sol inguinal bölgede lenf nodu

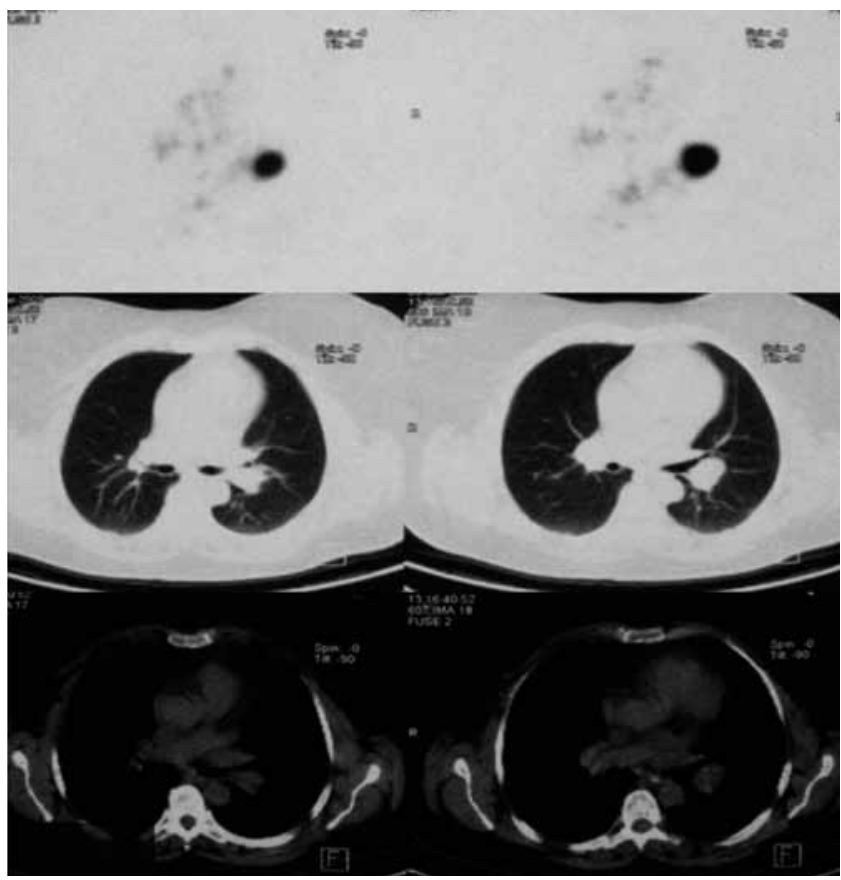

Resim 3: PET-BT'de sol hiler bölgede yoğun FDG tutulumu gösteren lenf nodu

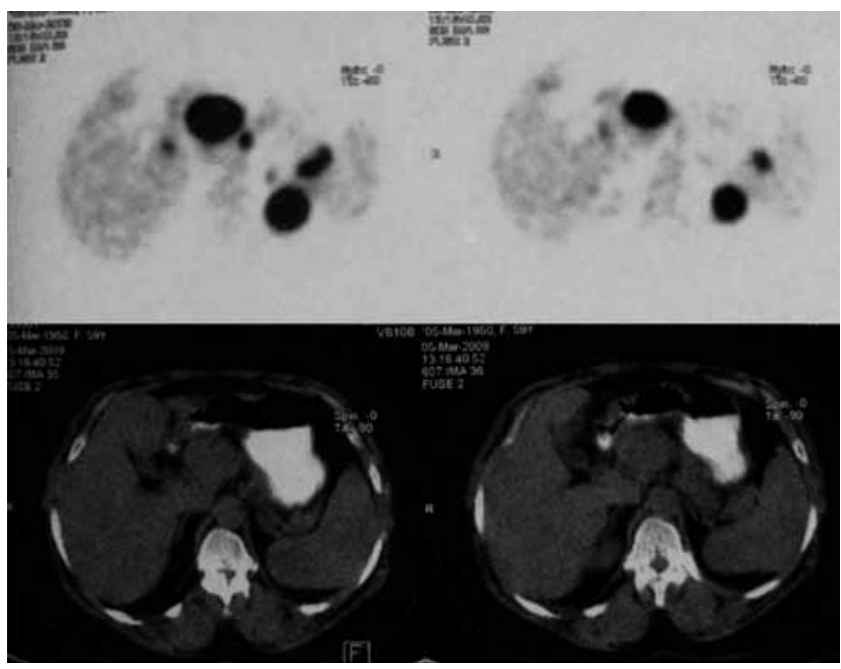

Resim 4: PET-BT'de pankreasta, peripankreatik alanda ve dalakta yoğun FDG tutulumu gösteren lezyonlar

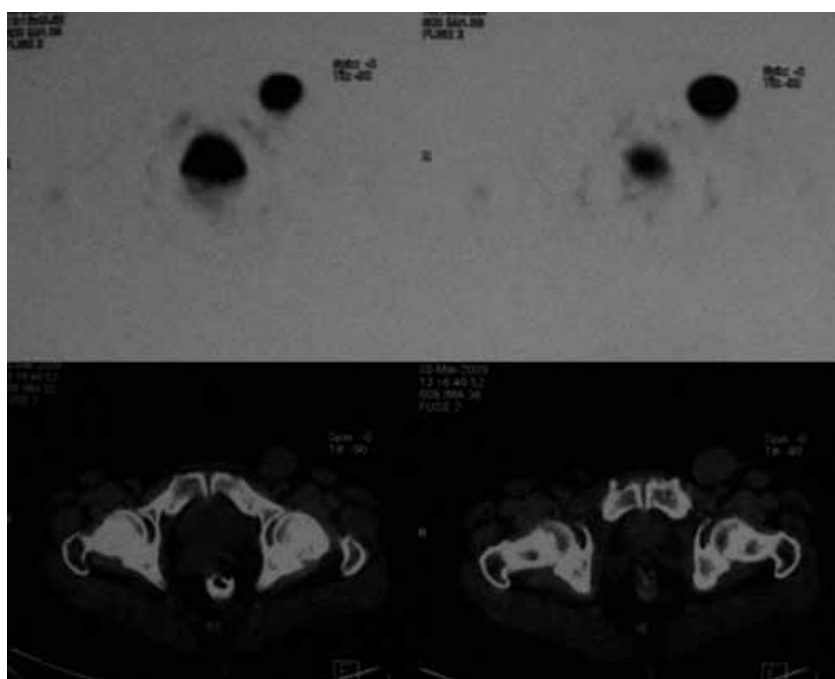

Resim 5: PET-BT'de sol inguinal bölgede yoğun FDG tutulumu gösteren lenf nodu

pankreatik kanalda genişleme saptanmadı. İntraabdominal ve retroperitoneal alanda lenf nodu görülmedi. Ancak sol inguinal bölgede $6 \times 5 \mathrm{~cm}$ boyutlarında lenf nodu tespit edildi (Resim 2). PET-BT (Siemens Biograph 6 Entegre, Erlangen Germany) tetkikinde; sol hiler alanda $3 \mathrm{~cm}$ çapında, sağ hiler alanda $1 \mathrm{~cm}$ çapında (Resim 3), batında en büyüğü pankreas gövde bölümünde olmak üzere, dalakta, peripankreatik alanda (Resim 4) ve sol inguinal alanda (Resim 5) birkaç adet yoğun patolojik Florodeoksiglikoz (FDG) tutulumu tespit edildi. FDG tutulumlarında standardize edilmiş en fazla tutulum (SUV max) değerleri 30.948.8 arasında değişmekteydi. Sol inguinal bölgedeki lenf nodundan yapılan eksizyonel biyopside, yüksek dereceli yaygın B hücreli NHL tanısı konuldu ve tedavisi planlandı.

\section{TARTIŞMA}

NHL'ın pankreas tutulumu sınırlı, yaygın veya çok sayıda tekli nodüller şeklinde görülebilir. Ayırıcı tanıda öncelikle adenokarsinom ve pankreatit düşünülmelidir. Tek sayıda primer pankreatik lenfomada kitle genellikle tipik bir adenokarsinomdan daha büyüktür. Adenokarsinomlardan farklı olarak nadiren damar darlığına veya tıkanıklığına yol açar. NHL tümör etkisiyle ortaya çıkan veya kemoterapi sonrasında oluşan tümör lizisine bağlı olarak pankreatite neden olabilir $(3,4)$.

NHL'daki pankreatik lezyonların tanısında genellikle ultrasonografi (US), manyetik rezonans görüntüleme (MRG) ve bilgisayarlı tomografi (BT) kullanılır. US'de başlıca bulgu yaygın veya sınırlı hipoekoik pankreatik geniş- 
lemedir (5). BT'de genel olarak hipodens, homojen, solid lezyonlar olarak izlenir (6). Ancak, tümör kitlesi içinde küçük, heterojen alanlar ve bazı olgularda heterojen kontrastlanma da görülebilir $(3,7)$. MRG görüntüleme bulgularının da başlıca iki morfolojik karakteri bildirilmiştir (3). İlk olarak BT'deki kitleye karşllık gelmek üzere pankreas bezine göre T1 ağırlıklı görüntülerde düşük sinyal yoğunluklu sınırları iyi belirlenen homojen bir kitle görülür. T2 ağırlıklı görüntülerde hafif-orta derecede heterojen sinyal artışı gösterdiği saptanır. ikinci morfolojik görünümde pankreas bezine göre, kontrastsız $\mathrm{T} 1$ ve T2 ağırlıklı görüntülerde düşük sinyal intensitesi ve kontrastlı incelemelerde ise hafif ile orta derecede kontrastlanma izlenir (8).Yayınlarda, NHL'ın pankreas tutulumuna özgün PET-BT bulguları belirtilmemiş olup bizim olgumuzda yüksek FDG tutulumu (SUVmax değerleri 30.9-48.8 arasında değişmekte) göstermektedir.

Sonuç olarak pankreasta NHL çok az görülmekle birlikte; tek veya çok sayıda, iyi sınırlı, homojen iç yapıda, hafif kontrast tutulumu gösteren kitlesel lezyon varlığında, özellikle duktal obstrüksiyon eşlik etmediğinde, ayırıCı tanıda mutlaka düşünülmesi gerekir. Tanısında US, BT veya MRG oldukça yararlı bilgiler vermekte olup klinik ile birlikte değerlendirilmesi ve sitopatolojik inceleme önemlidir. PET-BT ise hastalığın yayılımını göstermede kullanılabilir.

\section{KAYNAKLAR}

1. Ji Y, Kuang TT, Tan YS, et al. Pancreatic primary lymphoma: a case report and review of the literature. Hepatobiliary Pancreat Dis Int 2005; 4: 622-626.

2. Rack KA, Delabesse E, Radford-Weiss I, et al. Simultaneous detection of MYC, BVR1, and PVT1 translocations in lymphoid malignancies by fluorescence in situ hybridization. Genes Chromosomes Cancer 1998; 23: 220-226

3. Merkle EM, Bender G, Brambs HJ. Imaging findings in pancreatic lymphoma: differential aspects. AJR Am J Roentgenol 2000; 174 671-675.

4. Teefey SA, Stephens DH, Sheedy PF $2^{\text {nd }}$. CT appearance of primary pancreatic lymphoma. Gastrointest Radiol 1986; 11: 41-43.

5. Carroll BA, Ta HN. The ultrasonic appearance of extranodal abdominal lymphoma. Radiology 1980; 136: 419-425.

6. Prayer L, Schurawitzki H, Mallek R, Mostbeck G. CT in pancreatic involvement of non-Hodgkin lymphoma. Acta Radiol 1992; 33: 123127.

7. Van Beers $B$, Lalonde L, Soyer $P$, et al. Dynamic CT in pancreatic lymphoma. J Comput Assist Tomogr 1993; 17: 94-97.

8. Sağlam M, Yllmaz Mi, Mas MR, et al. A case of pancreatic Burkitt lymphoma: radiological findings. Diagn Interv Radiol 2009; 15: $39-42$. 